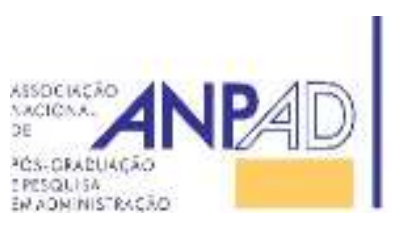
Available online at http://www.anpad.org.br/bar
BAR, Rio de Janeiro, v. 13, n. 1, art. 6, pp. 98-119, Jan./Mar. 2016 http://dx.doi.org/10.1590/1807-7692bar2016150283

\title{
Team Potency and Its Impact on Performance via Self-efficacy and Adaptability
}




\begin{abstract}
In sales, working together as a team for achieving individual performance is a relevant element. In this paper, we suggest a theoretical framework that analyzes the impact of team potency on subjective performance, according to two mechanisms: self-efficacy and adaptability. The hypotheses suggest that (a) team potency has a positive relationship with self-efficacy and adaptability; self-efficacy and adaptability impact performance (b) directly and (c) indirectly, through a mediating role; and (d) interpersonal climate quality moderates these associations. We did a national survey with 290 salespeople organized in 101 teams from a water purification company. We used multilevel analyses and results suggested that sales team potency has a main effect on self-efficacy and adaptability. Second, results showed that self-efficacy and adaptability explain subjective performance. Third, self-efficacy and adaptability mediate the association between team potency and individual performance. Fourth, we did not find support for a moderating role of interpersonal climate quality on team potency. Final remarks and future research are discussed in the paper.
\end{abstract}

Key words: team potency; adaptability; self-efficacy; salesperson performance. 


\section{Introduction}

Company performance is in many ways associated with the resourcefulness of its work teams (Clark \& Maggiti, 2012). Daily teamwork is one of the ways by which a company seeks to achieve its objectives in highly competitive times (Auh, Spyropoulou, Menguc, \& Uslu, 2014). In this highly competitive context, understanding the influence teamwork has on individual and organizational development and sales performance is of interest to marketing managers as a way to achieve better results.

Researchers seek to delimit ideal conditions for sales team performance based upon variables that contribute to understanding performance antecendents (Lester, Meglino, \& Korsgaard, 2002). In this context of different conditions, research about team potency (Gully, Incalcaterra, Joshi, \& Beaubien, 2002; Jong, Ruyter, \& Wetzels, 2005, 2006), interpersonal climate (Ahearne, Mackenzie, Podsakoff, Mathieu, \& Lam, 2010; Gil, Rico, Alcover, \& Barrasa, 2005; Jong, Ruyter, \& Lemmink, 2004), selfefficacy (Cavazotte, Moreno, \& Bernardo, 2013; Chen, Casper, \& Cortina, 2001; Jong et al., 2006; Wang \& Netemeyer, 2002), and adaptability (Griffin \& Heskesh, 2005; Predmore \& Bonnice, 1994; Pulakos, Arad, Donovan, \& Plamondon, 2000; Verbeke, Belschak, Bakker, \& Dietz, 2008) have advanced the understanding of team resourcefulness by proposing theoretical and practical implications.

For Gully, Incalcaterra, Joshi and Beaubien (2002), team potency enhances performance, however, mixed results from other researchers, including Lester, Meglino and Korsgaard (2002), Ahearne, Mathieu and Rapp (2005), Jong, Ruyter and Wetzels (2005) and Ahearne, Mackenzie, Podsakoff, Mathieu and Lam (2010) indicate that the relationship isn't necessarily direct and that there is a need for further investigation. Therefore, other ways to study this relationship as a mediator or moderator should be explored. Thus, these mixed results offer insight for this current research.

There is evidence in the literature (Guzzo, Yost, Campbell, \& Shea, 1993; Lester et al., 2002) that team potency is the result of extrinsic (ex. interpersonal climate) and intrinsic (ex. self-efficacy) team factors and that individuals' extrinsic aspects enhance their adaptability (Weitz, Sujan, \& Sujan, 1986). These factors (ex. interpersonal climate, self-efficacy) can be seen as mechanisms to explain the ways in which team potency interferes with performance. Based on sales and team potency literature (Ahearne, Mathieu, \& Rapp, 2005; Ahearne et al., 2010; Jong et al., 2005; Weitz et al., 1986) we propose and analyze four little-explored avenues in this work. They are: (a) the direct effects adaptability and selfefficacy have on sales performance; (b) how team potency as a group element affects two individual characteristics, those being adaptability and self-efficacy; (c) the indirect impact of team potency on performance as mediated by adaptability and self-efficacy; and (d) the effect team potency has to mediate interpersonal climate. In this context, the article adds four contributions to sales literature by focusing on intrinsic and extrinsic sales personnel characteristics, aspects of interpersonal climate quality, and group and team aspects to explain sales performance.

First, with few exceptions (Ahearne et al., 2005; Verbeke, Dietz, \& Verwaal, 2011), there is a lack of marketing studies, specifically in sales, that use the two elements of adaptability and self-efficacy as antecedents to individual sales person performance. This is because most such studies come from psychology (Griffin \& Heskesh, 2003; Hughes, Le Bon, \& Rapp, 2013; Predmore \& Bonnice, 1994). In this work we argue that both elements directly impact sales performance.

Second, we defend a new avenue for explaining team performance, through team potency. In other words, we propose the existence of a mediating effect from adaptability and self-efficacy in related to team potency and performance. These two mediated results occur because working on highly effective teams and via highly developed social relationships (Hughes et al., 2013; Lindell \& Brandt, 2000; Sparrowe, Liden, Wayne, \& Kraimer, 2001; Verbeke et al., 2008) generates confidence and capacity for adaptability, which produce better results (Ahearne et al., 2010; Chakrabarty, Brown, \& Widing, 2013; Jong et al., 2006). Results confirm these two mediating effects. 
Third, the ability to learn and perform interdependent tasks - inherent to salespeople who exhibit adaptability - is an aspect antecedent to individual performance (Weitz et al., 1986). The ability to deal with conflict, exchange information and implement information - intrinsic to self-efficacious individuals - are also strong predictors of performance and possibly can be promoted by companies that don't have sufficiently trained leaders for the teams that need them (Auh et al., 2014). In this work, we confirm that the group element (team potency) directly affects individual sales person elements (adaptability and self-efficacy).

Fourth, we add that having collaborators working in teams creates synergies among members who have different abilities and experiences (Ahearne et al., 2005). This synergy can be weakened or strengthened depending upon the quality of team climate (Ahearne et al., 2010). Related to this is how collective beliefs, team potency and interpersonal climate quality interact to offer a strong predictor of sales performance. This article applies Ahearne et al.'s (2005) research into the moderating effect consensus has on climate. Based upon Lindell and Brandt (2000), we include a fifth element - climate quality - with similar results to Ahearne et al. (2005), who did not confirm a moderating effect.

After this introduction, the work is divided into: a section on the theoretical model about team potency, self-efficacy, adaptability and interpersonal climate quality. Next, we detail methodological procedures, scales and research operationalization. After that we present results and in the last section discuss them.

\section{Framework and Hypotheses}

In this article we propose a framework that examines the direct relationships between sales team potency and individual aspects, such as self-efficacy and adaptability, with interpersonal climate quality as a moderator and adaptability and self-efficacy as mediators.

Monteiro (2014) performed a bibliometric survey of articles published between 2009 and 2013 in 30 Brazilian journals ranked between Qualis A1 and B3 in ANPAD during those same years. Results showed only 25 articles related to one or more of the selection criteria, but none with applications to marketing or sales. Therefore it is important to emphasize that this work began first from a bibliometric survey and second from fieldwork.

\section{Team potency and adaptability}

Team potency is the belief shared by team members that their group is effective at achieving assigned results (Guzzo et al., 1993). In this work, we suggest that team potency has an impact on individual adaptability due to two primary reasons. First, the effect occurs through leadership. Studies show that leadership improves a team's potency capacity (Ahearne et al., 2010; Lester et al., 2002) through charisma, which tends to influence member adaptability (Griffin \& Hesketh, 2003) regarding sales tasks. Further evidence identifies that behavior aimed at clients by immediate supervisors promotes sales person adaptability towards actions taken with clients (Chakrabarty et al., 2013).

Teams with potency exhibit mutual aid, interpersonal information exchange and assistance, which are related to individual adaptability (Hughes et al., 2013). Assistance between peers can include beating goals, performing market research or filling out documents related to sales or registration activities. Ahearne et al. (2010) highlights this reciprocal subsidy procedure, showing that support behavior within a team was the mechanism that favored team member adaptability. Thus, we propose:

$\mathbf{H}_{1}$ : Team potency positively impacts sales person adaptability. 


\section{Adaptability and performance}

Verbeke, Dietz and Verwaal (2011) explained that the degree of sales person adaptability is important to sales performance since it is conceived of as the seller's capacity to use object knowledge as much as process knowledge to establish sales strategies that meet client needs. In this sense, what is expected is that individual adaptability results in the exchange and implementation of information (Hughes et al., 2013) about an object (the product or service) and about a process (sale, post-sale, exchange). Exhibiting these characteristics of knowledge exchange, the individual tends to improve their effectiveness in executing tasks and can obtain better results, increasing individual performance.

Empirically, Predmore and Bonnice (1994) encountered a positive relationship between adaptability and sales success. Ahearne, Jones, Rapp and Mathieu (2008) showed an association between adaptability and sales person performance in the context of technology use. Finally, Chakrabarty, Brown and Widing (2013) found evidence of adaptability impact on performance for American sales personnel. Therefore:

$\mathbf{H}_{2}$ : Adaptability has a positive impact on sales person performance.

\section{Team potency and self-efficacy}

Self-efficacy is the individual belief in capability to realize a specific task (Jones, 1986; Wood \& Bandura, 1989). Team potency should elevate self-efficacy because teams with potency show a collective belief in themselves (Guzzo et al., 1993) which, in a certain way, generates the habit and confidence to focus on each others' actions (Gully et al., 2002), improving self-efficacy. In this context, the process of believing in the results, the goals and the company is a possible source of synergistic team potency that can elevate sales person performance. Therefore, we believe that collective belief (Marks, Mathieu, \& Zaccaro, 2001), the habit of efficacy and trust in each other in a work environment are conductor mechanisms that associate team potency with self-efficacy.

Wood and Bandura (1989) show that there is a relationship between past performance and selfefficacy. Lester et al. (2002) found similar results concerning the role past performance has on team potency. These two works offer theoretical and empirical support that working in teams that exhibit potency tends to elevate individual performance through trust and belief. Therefore:

$\mathbf{H}_{3}$ : Team potency has a positive impact on sales person self-efficacy.

\section{Self-efficacy and performance}

According to Wood and Bandura (1989), self-efficacy leads to professionals putting forth more effort towards task execution. If a sales professional exhibits greater effort in performing an activity, there seems to be a nexus of causality which indicates better results (Hartline \& Ferrell, 1996). We suggest that those sales personnel with greater levels of self-efficacy tend to have better performance via persistence in sales-related behavior (Gist \& Mitchell, 1992), effort (Ahearne et al., 2005; Hartline $\&$ Ferrell, 1996) and via capacity for action (Bandura \& Locke, 2003). In this sense, these elements are conductors for the positive effects self-efficacy has on individual performance, supporting the elaboration of another hypothesis. Furthermore, there is evidence that with an increase in task effort and engagement, self-efficacy impacts sales person performance (Lai \& Chen, 2012; Wang \& Netermeyer, 2002) and generates better results for activities (Cavazotte et al., 2013; Chen et al., 2001). Thus, we suggest:

$\mathbf{H}_{4}$ : Self-efficacy has a positive impact on sales person performance. 


\section{Moderating effects of interpersonal climate quality}

The quality of team interpersonal climate can be understood as the distinct patterns of collective beliefs about the interpersonal processes that include conflict management (Auh et al., 2014). Therefore, the quality of interpersonal climate involves a certain level of conflict, however, without undesirable or reactive and/or related to eventual interpersonal misunderstandings between team members (Cavazotte, et al., 2013; Lira, Ripoll, Peiró, \& Orengo, 2008).

There is reason to suggest that climate quality is a moderator on the effects of team potency. Initially, we propose that when a team exhibits high potency and a good interpersonal climate (i.e. without conflict or with conflict under certain acceptable levels) these conditions interact to improve sales person capacity for adaptation. This is because they have greater information to call upon when acting (Auh et al., 2014), greater assertiveness and freedom to mimic others' behavior (Bandura, 1993). Hence, the effects team potency has on adaptability are amplified in the existence of higher levels of climate quality. Jong et al. (2005) suggest that team potency can be improved through feedback programs and by work teams that share information that creates an exchange of support for customer service. Feedback activities in groups elevates interpersonal climate quality to mutual benefit and, when this interacts with team potency, amplifies the positive effects of salesperson adaptability.

Third, Ahearne et al. (2010) aimed to identify the moderating role of consensus on group interpersonal climate concerning the relationship between empowerment and interpersonal climate quality. The authors did not find support and results suggest that new research investigate why approximately $60 \%$ of the effect of interpersonal climate quality on performance is direct and not from proposed moderating influences (ex. team potency, intragroup assistance, and effort). The authors' explanation for a non-significant result is that "when a team's ability to handle conflicts, manage affect, and motivate each other is low, being certain of this is no worse than being uncertain of this" (p. 467). We expand this discussion on climate consensus to include interpersonal climate quality, positioning the latter as a moderator, in order to examine the next supposition.

H$_{5}$ : Interpersonal climate quality moderates the relationship between team potency and sales person adaptability, making it stronger.

Wang and Netemeyer (2002) showed a relationship between self-efficacy and individual results. Complimenting this, Lindel and Brandt (2000) point out that "the incremental variance of climate consensus and its interaction with climate quality in predicting organizational outcomes" (p. 343), suggesting a possible interaction between team potency and interpersonal quality climate concerning self-efficacy.

There is evidence of a moderating effect for climate quality in the relationship between team potency and individual self-efficacy through two conditions: customer satisfaction and information exchange. First, Bitner, Booms and Mohr (1994), Jong et al. (2006) and Schneider, Salvaggio and Subirats (2002) indicate a relationship between interpersonal climate quality and customer satisfaction. Such an association is seen to improve team potency and elevate individual capacity (i.e. self-efficacy). Therefore, since individual results are a consequence of self-efficacy (Wang \& Netemeyer, 2002) and interpersonal climate quality (Lindel \& Brandt, 2000) and because climate influences customer satisfaction, which is a final result, there is a possible positive interaction between team potency and self-efficacy.

Second, we believe that teams which exhibit high potency - collective belief in the team - have sales personnel that present higher than average levels of self-efficacy when combined with an environment that is conducive of good interpersonal climate. This is even better if there is a higher level of information exchange (Hughes et al., 2013), greater behavioral mimicking (Bandura, 1993), better adaptability (Verbeke et al., 2011), and capacity for implementation of shared information (Menguc, Auh, \& Uslu, 2013). Such elements foment an environment with better quality interpersonal relationships and with this the climate can have an amplifying role in the relationship, as a moderator. Thus: 
$\mathbf{H}_{6}$ : Interpersonal climate quality moderates the relationship between team potency and selfefficacy, making it stronger.

\section{Indirect effects of potency}

Verbeke et al.'s (2011) meta-analysis evaluated 14 effects the degree employee adaptability has on performance, showing an expressive result for this association $(\beta=0.27 ; p<0.05)$. Based upon this consolidated discovery, we suggest a mediating effect for adaptability in the relationship between potency and performance. The argument we present here centers on the fact that teams with potency exhibit support behavior and information exchange, which are related to adaptability (Hughes et al., 2013). These two elements (i.e. Support and information exchange) tend to facilitate the adjustment of sales activities, which tend to impact, by consequence, sales person performance. Therefore, adaptability tend to mediate the relationship between team potency and sales person performance through social support, interpersonal relationships, information exchange, and the development of supportive relationships (Tucker, Pleban, \& Gunther, 2010). Furthermore, Weitz, Sujan and Sujan (1986) suggested that an individual sales person's knowledge capacity, coming from self-management and the environment (elements which help team potency), leads to adaptation, which is associated with performance. Hence:

$\mathbf{H}_{7}$ : Sales person adaptability mediates the relationship between Team Potency and performance.

According to Gist and Mitchell (1992), there are three elements that lead to self-efficacy. Analysis of task demands, that is, how much of an assigned task is within the professional's skill set. When skill set is greater, task engagement is also greater. Second, analysis of experience when a task is performed by a professional, in the sense of understanding interest, as experience, in performing the task and/or if the existing experience is sufficient (Gist \& Mitchell, 1992). Third, analysis of the number of skills that are necessary to execute the task with motivation. We believe that these three elements (primarily the mechanism about skill quantity discussed by Guzzo et al., 1993) can be caused by sales team potency effect on the individual and thus individual performance results tend to be elevated. In this context, selfefficacy can be the mechanism that transmits the indirect effect of team potency on performance through these three elements.

Another mechanism that might help explain the mediating effect is communication-cooperation. Lester et al. (2002) proposed that team potency generates communication-cooperation, which results in performance. This proposal shows that conversation processes between individuals and mutual collaboration tend to result in better performance, feeding back into the team. Therefore, team potency influences communication-cooperation, which in turn elevates self-efficacy, which promotes better sales person performance. Thus:

$\mathbf{H}_{8}$ : Sales person self-efficacy mediates the relationship between Team Potency and performance.

The proposed conceptual model contemplates team-level variables of team potency and interpersonal climate quality, which take the form of a crosshatch pattern in the conceptual model. The other elements of self-efficacy, adaptability and performance are measured at the individual level. The preponderant role of team potency as a direct source of individual aspects and indirect source of performance, via the two mediators self-efficacy and adaptability, is predominant. Interpersonal climate quality as a moderator is also evident.

In Figure 1, the solid arrows denote a direct effect while the broken arrows denote moderating effects. The gray boxes represent team-level data and white boxes represent individual-level data. 


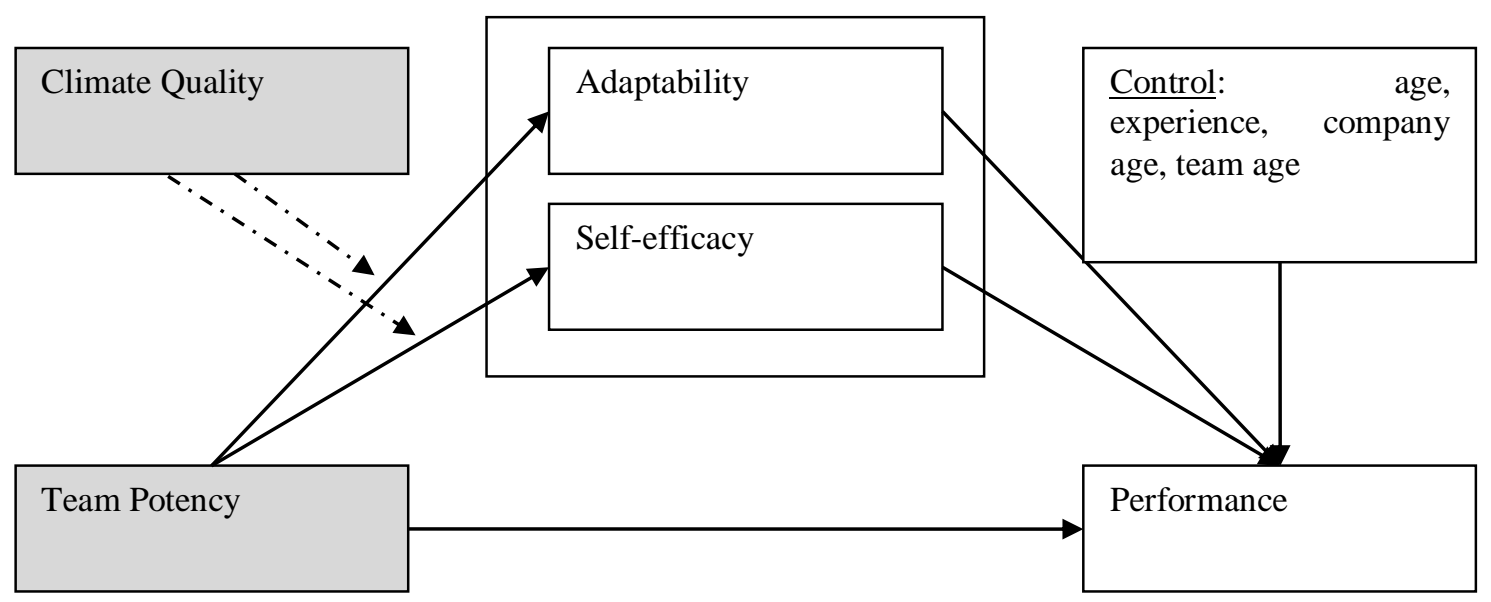

Figure 1. Proposed Conceptual Model

\section{Research Design}

The research was realized with 290 salespeople working water filters and filter elements at 144 Brazilian branches of a company headquartered in the state of Paraná. The company's sales structure consists of regional, national, and branch managers. Each of the 144 branches exclusively sells company products. Branches have common goals (for salespeople and for teams) and results are compared at the branch, regional and national levels.

To collect data, the company's marketing director sent a link about the research to employees via the internet. Afterwards, we sent five other requests for a response from 144 branches, using employee emails provided by the company, with $58(40 \%)$ returning them. We defined a group or team as those with a minimum of 2 respondents per branch, which resulted in 54 groups. Next, we entered into contact with the other branches, that had not initially responded, asking for responses from salespeople to the mailed survey. Finally, the company organized training with all of the branches, during which, with authorization from the marketing director, we were able to apply the questionnaire to branches that had not previously responded. Thus, we finalized data collection from 101 teams ( $71 \%$ of the branches) with two or more salespeople, and with 4 branches with only one answer, which were not included in analysis because they did not constitute a team.

In order to measure the theoretical model constructs we used scales that had already been validated in the literature. These are presented in the conceptual definitions, and Annex A describes operational definitions. Annex B shows adjustments to the model. According to Jones (1986), selfefficacy is the individual belief about self-capacity to organize and execute actions required for completing tasks, in line with Jong, Ruyter and Lemmink (2004) and Wood and Bandura (1989). In our work, the self-efficacy construct is operationalized by 6 items adapted from Jones (1986). According to Spiro and Weitz (1990), adaptability is a professional's capacity to adapt their behavior to customers' interpersonal demands. This construct is operationalized by 7 items adapted from Spiro and Weitz (1990). In relation to measuring subjective performance in sales, the questionnaire includes items about reaching goals, professional performance and achieving objectives. Thus, following Verhoef and Leeflang's (2009) proposal, this work uses four measurements to measure subjective sales performance.

For Guzzo, Yost, Campbell and Shea (1993), team potency is the collective belief that the team can be effective. This construct is measured by 5 items adapted from Guzzo et al. (1993). According to Ahearne et al. (2010), salesperson responses to the items from the scale for team potency were transformed into an average for each group, thus, aggregating individual data onto the team to create a new mean score. 
Marks, Mathieu and Zaccaro (2001) defined interpersonal climate quality as the individual perception and collective belief about team capacity for managing conflicts in a positive manner, about motivation and trust-building among the team. This construct is operationalized by 3 items from Ahearne et al. (2010) in which those interviewed evaluated conflict management, collective trust and personal relationship management on the team. Salesperson responses were transformed into a team average, following the same procedure for team potency and conforming to Ahearne et al. (2010).

All scales were 7-point Likert in design, varying from $1=$ completely disagree/almost never to 7 $=$ completely agree/always. Control variables included total sales experience in amount of time, total amount of time working at the company, time working on the sales team, and salesperson age, all measured in years. The choice of these variables was made because (a) they were used in other studies (Ahearne et al., 2010; Ahearne, Jones, Rapp, \& Mathieu, 2008), (b) they were consistent with the research proposal, and (c) because they have the possibility to affect work results.

After developing the questionnaire with the cited scales, three marketing students answered it. This was done as a pre-test, which shows the face validity of the instrument for collecting data. Then the questionnaire was applied to a graduate-level class of 35 individuals and the results were analyzed. This analysis demonstrated that one of the self-efficacy items, originally a reverse question, compromised the capture of construct variation. Thus, the question was transformed to be positively worded. Based upon this pre-testing, the instrument was adjusted, consolidated and implemented in the present research.

\section{Model specifications}

In order to examine the hypotheses, we estimated three models using multiple regression. The first model presents only the salesperson covariates' impact on performance. The second model describes the association of the covariates and the main effects of the sales persons on performance. The third model is complete and includes all of the previous effects as well as interactions between them (full model). The regression models were estimated with and without covariates, using a bootstrapping process with the help of Hayes' PROCESS ${ }^{\circledR}$ (2013). Results are described in Table 2.

\section{Results}

Of research respondents, $51.4 \%$ were male. On average, they had worked on the teams for 3 years, and $41 \%$ identified as a salesperson. Combined, those that identified as both sales managers and salespeople made up $71 \%$ of the sample. In this work the professional on a sales team involved in customer service activities is understood to be a salesperson. $7.2 \%$ of the sample was composed of professionals that act as both a salesperson and a director of sales. $53.6 \%$ of salespeople receive awards if they accomplish their goals.

We used factorial analysis with Varimax solution to analyze measurement scales. An initial round indicated a factorial problem. In this extraction we verified a crossed load between item 6 on the selfefficacy scale and the adaptability construct. Thus, for convergent and discriminant validity we took item AE6 out and performed a new factorial analysis, reaching a rotated solution with five divergent factors (constructs).

Table 1 demonstrates Pearson correlations in the lower diagonal and Spearman correlations in the upper diagonal. Adaptability and self-efficacy can be seen to be significantly related to individual performance, team potency and interpersonal climate quality, and among themselves. Time and age are in years, with average time on the team being 2.91 years $(\mathrm{DP}=2.09)$. 
Table 1

\section{Pearson and Spearman Coefficients}

\begin{tabular}{|c|c|c|c|c|c|c|c|c|c|}
\hline & Constructs & 1 & 2 & 3 & 4 & 5 & 6 & 7 & 8 \\
\hline & $\begin{array}{l}\text { Level 1: Individual } \\
\text { responses }\end{array}$ & $\mathrm{N}=290$ & & & & & & & \\
\hline 1 & Self-efficacy & 1.00 & $0.63 * *$ & $0.55^{* *}$ & $0.28 * *$ & $0.33 * *$ & -0.01 & 0.07 & $0.12^{*}$ \\
\hline 2 & Adaptability & $0.53^{* * *}$ & 1.00 & $0.47 * *$ & $0.32 * *$ & $0.32 * *$ & $-0.16^{* *}$ & 0.02 & $0.12^{*}$ \\
\hline \multirow[t]{2}{*}{3} & Individual Performance & $0.52^{* * *}$ & $0.45^{* * *}$ & 1.00 & $0.42 * *$ & $0.36 * *$ & $-0.23 * *$ & $-0.11^{*}$ & -0.02 \\
\hline & Level 2: Team responses & $\mathrm{N}=101$ & & & & & & & \\
\hline 4 & Team Potency & $0.29^{* * *}$ & $0.32^{* * *}$ & $0.39^{* * *}$ & 1.00 & $0.59 * *$ & $-0.27 * *$ & $-0.23 * *$ & $-0.18 * *$ \\
\hline \multirow[t]{2}{*}{5} & Interpersonal Climate Quality & $0.34^{* * *}$ & $0.29^{* * *}$ & $0.35^{* * *}$ & $0.53^{* * *}$ & 1.00 & -0.06 & 0.02 & -0.10 \\
\hline & Covariates & & & & & & & & \\
\hline 6 & Age & 0.05 & -0.08 & $-0.21^{* * *}$ & $-0.17^{* *}$ & -0.05 & 1.00 & $0.61 * *$ & $0.21 * *$ \\
\hline 7 & Sales Experience & $0.13^{*}$ & $0.14^{*}$ & 0.03 & $-0.12^{*}$ & 0.05 & $0.56^{* * *}$ & 1.00 & $0.29 * *$ \\
\hline 8 & Time at the Company & 0.10 & $0.11^{*}$ & 0.04 & $-0.16^{* *}$ & -0.06 & $0.39^{* * * *}$ & $0.49^{* * *}$ & 1.00 \\
\hline \multirow[t]{3}{*}{9} & Time on the Team & 0.05 & 0.04 & 0.02 & $-0.19^{* *}$ & $-0.13^{*}$ & $0.43^{* * *}$ & $0.51^{* * *}$ & $0.84^{* * *}$ \\
\hline & Average & 5.39 & 5.50 & 5.24 & 5.44 & 5.36 & 38 & 9.52 & 3.70 \\
\hline & Standard Deviation & 0.96 & 1.02 & 1.13 & 1.11 & 0.98 & 8.07 & 6.43 & 2.20 \\
\hline
\end{tabular}

Initially, the data show a positive results for the influence of team potency on adaptability $(\beta=$ $0.24, p<0.01$ ), supporting hypothesis $\mathrm{H}_{1}$. In this way, the greater the team potency, the more salespeople exhibit capacity to adapt their actions to the performance of their professional activities and sales activities expressed via adaptability (Weitz et al., 1986). This finding is expected and matches Hughes, Le Bon and Rapp (2013), Tucker, Pleban and Gunther (2010), and Ahearne et al. (2010).

The effect team potency has on sales person self-efficacy shows an expected value $(\beta=0.18$, $p<0.01)$ which supports hypothesis $\mathrm{H}_{3}$. This is congruent with Jong et al.'s (2005) results. More potent teams are characterized by an increase in self-efficacy of their salespeople, possibly related to a greater belief in the skills and knowledge about tasks that must be executed in the course of professional duties. Therefore, the results are coherent with Bandura (1993) and Lester et al. (2002) and show that team aspects affect salespeople, as found in Lira, Ripoll, Peiró and Orengo (2008) and Wood and Bandura (1989).

It is worth pointing out that when self-efficacy is the variable to be explained, $\mathrm{R}^{2}$ was $13.9 \%$. This indicates how much an individual's self-efficacy is affected by aspects extrinsic to the individual and intrinsic to the team. The variance explained for adaptability is $\mathrm{R}^{2}=12.9 \%$.

The moderating role of interpersonal climate quality in amplifying the effect of team potency was analyzed next. The moderating effects of interpersonal climate quality on team potency were not significant for adaptability $(\beta=0.05, p=$ n.s. $)$ or self-efficacy $(\beta=0.049, p=$ n.s. $)$. In other words, when interpersonal climate quality was added to the equation for explaining of the dependent variables adaptability and self-efficacy, the added values did not significantly alter the curve slopes, even though the direction was as expected. Thus, these results demonstrate that hypotheses $\mathrm{H}_{5}$ and $\mathrm{H}_{6}$ were not supported. 
As can be seen in Figure 2, interpersonal climate quality amplifies the positive effect potency has on adaptability. This was the same result as seen in the plot for self-efficacy, however, the moderating effect was not significant.

We then examined hypotheses $\mathrm{H}_{2}$ and $\mathrm{H}_{4}$, which propose a direct relationship between selfefficacy and performance (Table 3). Hypothesis $\mathrm{H}_{2}$, which describes the relationship of influence that adaptability has on individual performance, is supported $(\beta=0.188, p<0.01)$. This result demonstrates that adaptability is a predictor of individual performance for salespeople, as also found in Ahearne et al. (2008), Chakrabarty et al. (2013) and Verbeke et al. (2011).

Hypothesis $\mathrm{H}_{4}$ was also supported $(\beta=0.42, p<0.001)$, and significant with the expected direction. Data show that the greater a sales person's self-efficacy, the greater their individual performance. This result is in line with Cavazotte, Moreno and Bernardo (2013), Lai and Chen (2012), and Wang and Netemeyer (2002). 
Table 2

\section{Regression Coefficients for Team Effects on Salespeople}

\begin{tabular}{|c|c|c|c|c|c|c|c|c|c|c|c|c|}
\hline \multirow[t]{3}{*}{ Independent Constructs } & \multicolumn{6}{|c|}{ Self-efficacy } & \multicolumn{6}{|c|}{ Adaptability } \\
\hline & \multicolumn{2}{|c|}{ Model 1} & \multicolumn{2}{|c|}{ Model 2} & \multicolumn{2}{|c|}{ Model 3} & \multicolumn{2}{|c|}{ Model 1} & \multicolumn{2}{|c|}{ Model 2} & \multicolumn{2}{|c|}{ Model 3} \\
\hline & $\operatorname{Beta}(\beta)$ & t Value & $\operatorname{Beta}(\beta)$ & t Value & $\operatorname{Beta}(\beta)$ & t Value & $\operatorname{Beta}(\beta)$ & t Value & $\operatorname{Beta}(\beta)$ & $\mathrm{t}$ Value & $\operatorname{Beta}(\beta)$ & t Value \\
\hline \multicolumn{13}{|l|}{ Control Variables } \\
\hline Sales person age & -0.059 & -0.778 & 0.008 & 0.111 & 0.007 & 0.092 & -0.208 & $-2.772^{* *}$ & -0.143 & $-1.981^{*}$ & -0.145 & $-1.999^{*}$ \\
\hline Experience & 0.057 & 0.706 & -0.036 & -0.465 & -0.044 & -0.563 & 0.193 & $2.416^{*}$ & 0.134 & 1.722 & 0.126 & 1.605 \\
\hline Time at the Company & 0.193 & 1.714 & 0.150 & 1.418 & 0.138 & 1.297 & 0.178 & 1.611 & 0.166 & 1.558 & 0.154 & 1.433 \\
\hline Time on the Team & -0.116 & -0.977 & 0.036 & 0.317 & 0.054 & 0.471 & -0.223 & -1.911 & -0.122 & -1.069 & -0.103 & -0.886 \\
\hline \multicolumn{13}{|l|}{ Direct effects } \\
\hline Team Potency $\left(\mathrm{H}_{1}, \mathrm{H}_{3}\right)$ & & & 0.185 & $2.721^{* *}$ & 0.180 & $2.630^{* *}$ & & & 0.240 & $3.500^{* *}$ & 0.234 & $3.404^{* *}$ \\
\hline Interpersonal Climate $\mathrm{Qu}$ & lity & & 0.267 & $3.892^{* * *}$ & 0.263 & $3.876^{* * *}$ & & & 0.136 & $1.998^{*}$ & 0.135 & $1.984^{*}$ \\
\hline \multicolumn{13}{|l|}{ Moderating Effects } \\
\hline \multicolumn{5}{|c|}{$\begin{array}{l}\text { Team Potency } \times \text { Interpersonal Climate Quality } \\
\left(\mathrm{H}_{5}, \mathrm{H}_{6}\right)\end{array}$} & 0.049 & 0.864 & & & & & 0.050 & 0.889 \\
\hline Adjusted $\mathrm{R}^{2}$ & \multicolumn{2}{|c|}{0.003} & \multicolumn{2}{|c|}{0.139} & \multicolumn{2}{|c|}{0.138} & \multicolumn{2}{|c|}{0.034} & \multicolumn{2}{|c|}{0.129} & \multicolumn{2}{|c|}{0.128} \\
\hline VIF (Multicolinearity) & \multicolumn{2}{|c|}{4.058} & \multicolumn{2}{|c|}{4.311} & \multicolumn{2}{|c|}{4.462} & \multicolumn{2}{|c|}{4.058} & \multicolumn{2}{|c|}{4.311} & \multicolumn{2}{|c|}{4.462} \\
\hline$F$ (model) & \multicolumn{2}{|c|}{1.207} & \multicolumn{2}{|c|}{$8.791^{* * *}$} & \multicolumn{2}{|c|}{$7.636^{* * *}$} & \multicolumn{2}{|c|}{$3.521^{* *}$} & \multicolumn{2}{|c|}{$8.110^{* * *}$} & \multicolumn{2}{|c|}{$7.059^{* * *}$} \\
\hline
\end{tabular}

Note. Beta $(\beta)$ : Standardized regression coefficients. $* * * \mathrm{p}<0.00 ; * * \mathrm{p}<0.01{ }^{*} \mathrm{p}<0.05$. VIF $=$ variance inflation factor. 


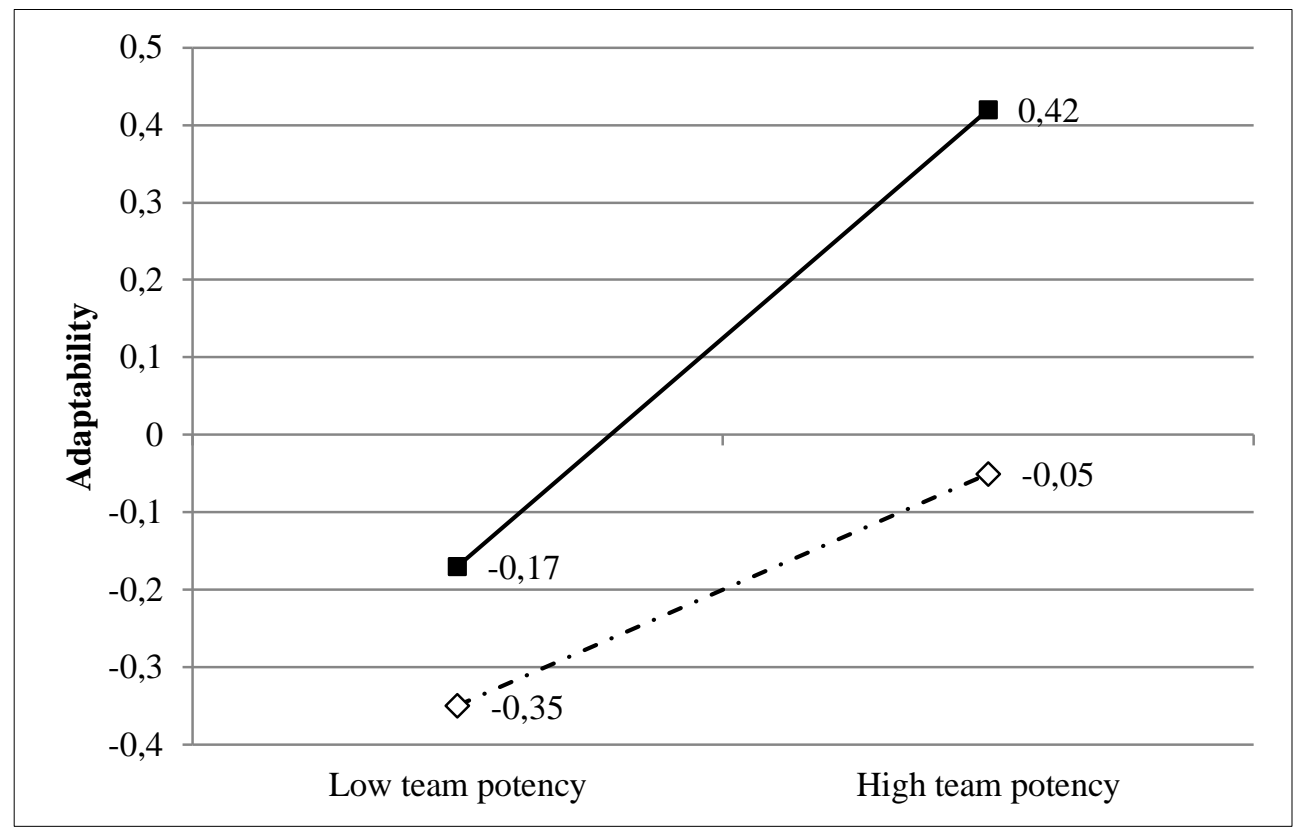

$-\prec \diamond \cdot . \cdot$ Low quality interpersonal climate

Figure 2. Moderating Effect of Climate Quality on Adaptability

The level of variance explained for performance by the control variables $(6 / 9 \%)$ is much lower than the level of variance explained by the use of self-efficacy and adaptability (35.4\%) generating a significant difference in variation of $29 \%(\Delta F=27.348, p<0.000)$.

Table 3

Regression Coefficients for Individual Performance

\begin{tabular}{|c|c|c|c|c|}
\hline \multirow[t]{2}{*}{ Independent Constructs } & \multicolumn{2}{|c|}{ Model 1} & \multicolumn{2}{|c|}{ Model 2} \\
\hline & Beta $(\beta)$ & t Valor & Beta $(\beta)$ & t Valor \\
\hline \multicolumn{5}{|l|}{ Control Variables } \\
\hline Sales Person Age & -0.345 & $-4.949^{* * *}$ & -0.289 & $-4.852^{* * * *}$ \\
\hline Experience & 0.172 & $2.330^{*}$ & 0.063 & 1.001 \\
\hline Time at the Company & 0.096 & 0.905 & -0.028 & -0.308 \\
\hline Time on the Team & -0.001 & -0.012 & 0.106 & 1.163 \\
\hline \multicolumn{5}{|l|}{ Direct Effects } \\
\hline Adaptability $\left(\mathrm{H}_{2}\right)$ & & & 0.188 & $3.267^{* *}$ \\
\hline Self-efficacy $\left(\mathrm{H}_{4}\right)$ & & & 0.423 & $7.548^{* * *}$ \\
\hline Adjusted $\mathrm{R}^{2}$ & \multicolumn{2}{|c|}{0.069} & \multicolumn{2}{|c|}{0.354} \\
\hline VIF (Multicolinearity) & \multicolumn{2}{|c|}{3.668} & \multicolumn{2}{|c|}{3.721} \\
\hline F (model) & \multicolumn{2}{|c|}{$6.389^{* * * *}$} & \multicolumn{2}{|c|}{$27.348^{* * * *}$} \\
\hline
\end{tabular}

Note. Beta ( $\beta$ ): Standardized regression coefficients. $* * * p<0.00 ; * * p<0.01 ; * p<0.05$.

Team potency had a direct and significant relationship with self-efficacy and with adaptability $\left(\mathrm{H}_{1}\right.$ and $\left.\mathrm{H}_{3}\right)$ and these two last conditions had an impact on individual performance $\left(\mathrm{H}_{2}\right.$ and $\left.\mathrm{H}_{4}\right)$. Based upon this evidence as pre-conditions (Baron \& Kenny, 1986) and using the PROCESS ${ }^{\circledR}$ model in SPSS 
(Hayes, 2013) we examined the two mediating effects $\left(\mathrm{H}_{7}\right.$ and $\left.\mathrm{H}_{8}\right)$. To this end, the independent variable (team potency), the dependent variable (individual performance), and proposed mediators (adaptability and self-efficacy) were inserted into PROCESS ${ }^{\circledR}$ to test the model for mediation (model 4).

The direct effect between team potency and adaptability was $a=0.318, p<0.00$ (Zhao, Lynch, \& Chen, 2010). The relationship between the mediators and individual performance was $b=0.356, p<$ 0.00 . The main influence of team potency on individual performance the effect was $c=0.393, p<0.00$. Finally, the indirect effect of potency on individual performance with the presence of the adaptability mediator in the regression equation was diminished to $c^{\prime}=0.279, p<0.00$. The Sobel test $=4.30$ $(p<0.000)$ and Hayes (2013) bootstrapping supported this mediation, since there wasn't a zero between the inferior $\left(\mathrm{CI}_{\text {lower }}=0.07\right)$ and superior $\left(\mathrm{CI}_{\text {upper }}=0.17\right)$ limits. The primary effect reduced from $b=0.393$ to $b=0.279(\Delta=0.11)$, but continued to be significant. These findings were the same with or without covariables. This result supports and $\mathrm{H}_{7}$ and endorses the argument about mediation found in Tucker $e t$ al. (2010) about the association between performance value and performance potency.

Using the same methods we tested self-efficacy for mediation value (Shrout \& Bolger, 2002). The effect between potency and self-efficacy was $a=0.282, p<0.00$. For the direct relationship between selfefficacy and individual performance the impact was $b=0.411, p<0.00$. For the direct relationship between potency and individual performance, the effect encountered was $c=0.393, p<0.00$. Finally, the effect for potency on individual performance with the presence of mediators in the regression equation was reduced to $c^{\prime}=0,275, p<0,00$. In other words, there was an indirect effect via adaptability of $b=0.11$ (being a multiplication of $b=0.393 * b=0.275$ ). Based upon these results we confirm the mediated of self-efficacy. The Sobel test $=4.24(p<0.000)$ and Hayes bootstrapping $(2013)$ support this mediation, because there was no zero value between the lower $\left(\mathrm{CI}_{\text {lowe }}=0,07\right)$ and upper $\left(\mathrm{CI}_{\text {upper }}=0,15\right)$ confidence intervals. The same results were encountered with or without covariables. In summary, both mediation results $\left(\mathrm{H}_{7}\right.$ and $\left.\mathrm{H}_{8}\right)$ encountered in this research are classified by the literature as partial mediation (Baron \& Kenny, 1986) or as complementary mediation (Zhao et al., 2010) converging towards the proposal our suggested conceptual model. Therefore, there is a reduction in the direct effects of team potency on salesperson performance when there are mediating variables, while the associations continue to be significant.

\section{Conclusions}

Based on the proposed theoretical model and conforming to the research about salespeople, we highlight four significant contributions for this work. First, it supports the existence of a relationship between team potency and salesperson adaptability. Thus, greater team potency improves salesperson capacity, in contact with customers, to adjust their behavior in a way that meets customer needs, sales demands and other organizational needs (Weitz et al., 1986). This adaptive capacity can occur due to the collective trust relationships that exist in the team which facilitate the execution of tasks and adaptation. Team potency can create an environment in which the individual feels free to modify their work behavior in the sales field. Furthermore, in a potent team the vendor feels that they must be aligned with the skills exhibited by the team, which can lead to greater result levels. In this way, highly potent teams exhibit support and information exchange behaviors (Hughes et al., 2013) that are related to adaptability (Weitz et al., 1986).

Second, the greater the team potency, the greater sales person self-efficacy. The importance of self-efficacy in sales resides in the capacity a worker has to increase performance through effort, becoming more persistent and learning to deal with the obstacles related to their quotidian tasks (Hartline \& Ferrell, 1996). Ahearne et al. (2010) commented that team potency increased the effort and engagement with tasks, in a facilitating role. Therefore, self-efficacy has the characteristic of elevating engagement with attributed activities (Bandura, 1993). Ahearne et al. (2010) and our results indicate that individual productivity can be increased through potent teams. Therefore, if a team isn't potent, 
professionals enter into a kind of vicious cycle in which they become less self-efficacious, which makes the team less potent and discourages achieving expected results through action (Lester et al., 2002).

Third, our work did not find a significant moderating relationship for interpersonal climate quality on the relationship between team potency and self-efficacy and individual adaptability. Ahearne et al . (2010) also didn't encounter empirical support related to moderation of climate of consensus. One explanation for the non-expressive results might be due to the level of how climate is measured. Schneider et al. (2002) points to a distinction between climate quality at the organizational level (which was called culture) and interpersonal climate quality at the team level (which was called common perception of a specific event and uniform expectations for member behavior). Understanding both qualities at both levels and the difference between consensus and climate might be a way to study moderation.

Fourth, starting with the assumption that team potency enhances trust an individual has about their capacity to execute tasks (Wood \& Bandura, 1989), we identified two direct relationships between team potency and adaptability and between team potency and self-efficacy. Thus, the element of group interaction, team potency, directly influences the other two individual elements. Given that self-efficacy has characteristics that increase task engagement (Bandura, 1993) and given that adaptability is the individual capacity to adapt to the group, routines and information exchange (Hughes et al., 2013; Weitz et al., 1986), these elements influence performance.

\section{Managerial Applications}

The capacity for information exchange between sales teams can increase team potency and suggest cross and up-selling. One example is when a telemarketing agent indicates that a client should substitute their filter and an external sales person receives the scheduling information to close the deal. Both professionals (agent and external sales person) perceive that the work of the other is fundamental to achieving their goals, which can increase team potency. If there wasn't an agent maybe the client couldn't be personally accessed, and if the external sales person didn't exist, it wouldn't be possible to transmit all of the information and complaints over the telephone. Thus, the exchange of information among agents, salespeople, managers and teams is fundamental for suggesting cross and up-selling.

A second managerial application can be attributed to the possibility for implementing changes in the way teams act collectively. Change and paradigm interruption can happen, for example, from the implantation of a new system, the adoption of a new product line, with the extinction of classic products, with new client prospectus, etc. Thus, it is expected that any new activity is less complex for a potent team (with individuals exhibiting greater adaptability) than for a non-potent team. In this sense, organizations can develop activities to monitor team potency and levels of adaptability for new challenges, goals and tasks.

\section{Limitations}

This research does have its limitations. One of these is its transverse cut. It seems that investigation between potency and performance must include a time factor. In a certain way, the theoretical reference used indicates that team potency helps foment team potency in following time period $\mathrm{m} t+1$, through performance and team efficacy. Jong et al. (2006), Jung and Sosik (2003), and Lester et al. (2002) suggest measuring an initial time and future time for comparison. It wasn't possible in this research to study different times, which is a limitation.

Another problem is in the antecedent relationship to team potency. Different antecedents for team potency have been investigated by Jong et al. (2005), Lester et al. (2002), and Jung and Sosik (2003). 
The focus of these works has primarily been on leadership of teams and companies. This research did not measure the antecedents of potency and leadership, which might indirectly interfere in levels of adaptability and self-efficacy.

Third, this research did not have data about sales team supervisors. In Gully et al. (2002) results showed that relationships between team potency and self-efficacy are moderated by the level of sales team supervision. One limitation of this study is in not analyzing the levels above (supervisor) or below (agents and employees) the team.

\section{Future Research}

Some suggestions for future research are, first, team leadership as a role to establish, support and facilitate achieving goals (Katzenbach \& Smith, 1993). Ad hoc tests in this present research indicate that when goals are clear for salespeople there is greater individual performance $\left(M_{\text {Goals }}=5.44, M_{\text {Goals non- }}\right.$ established $\left.=4.83, F_{1,288}=20,226, p<0.01\right)$ and greater team potency $\left(M_{\text {Goals }}=5.53, M_{\text {Goals non-established }}=5.25\right.$, $\left.F_{1,288}=4,290, p<0.04\right)$. Therefore, we suggest new research that evaluates leadership together with team potency and interpersonal climate quality in order to achieve goals.

Second, new interactions can be explored in future works. For example, moderating aspects such as: (a) support from other teams $\times$ team potency about global company performance (Menguc et al., 2013); (b) empowerment $\times$ management for results about team potency (Ahearne et al., 2005); (c) management for results $\times$ and team potency about information exchange (Clark \& Maggitti, 2012), and (d) variation in age $\times$ interpersonal climate quality about team information exchange can be analyzed (Gil et al., 2005). There is literature for these lines of thought and new works can address these conditions.

Third, we encountered mediating effects for adaptability and self-efficacy, but in isolated manners. Future works can suggest a dual mediation (Hayes, 2013) proposing that team potency impacts selfefficacy, which generates adaptability (Ahearne et al., 2005), and by consequence elevates performance. Understanding if with two mediators team potency affects results can be another avenue for new research.

\section{Acknowledgments}

The authors would like to thank for the comments from the reviewers, Francisco G. Vieira, Plínio Rafael Reis Monteiro and Olga Maria Pepece.

\section{References}

Ahearne, M., Jones, E., Rapp, A., \& Mathieu, J. (2008). High touch through high tech: the impact of salesperson technology usage on sales performance via mediating mechanisms. Management Science, 54(4), 671-685. doi: 10.1287/mnsc.1070.0783

Ahearne, M., MacKenzie, S. B., Podsakoff, P. M., Mathieu, J. E., \& Lam, S. K. (2010). The role of consensus in sales team performance. Journal of Marketing Research, 47(3), 458-469. doi: $10.1509 / \mathrm{jmkr} .47 .3 .458$

Ahearne, M., Mathieu, J., \& Rapp, A. (2005). To empower or not to empower your sales force? An empirical examination of the influence of leadership empowerment behavior on customer 
satisfaction and performance. Journal of Applied Psychology, 90(5), 945-955. doi: 10.1037/00219010.90.5.945

Auh, S., Spyropoulou, S., Menguc, B., \& Uslu, A. (2014). When and how does sales team conflict affect sales team performance? Journal of the Academy of Marketing Science, 42(6), 658-679. doi: $10.1007 / \mathrm{s} 11747-014-0368-7$

Bandura, A. (1993). Perceived self-efficacy in cognitive development and functioning. Educational Psychologist, 28(2), 117-148. doi: 10.1207/s15326985ep2802_3

Bandura, A., \& Locke, E. A. (2003). Negative self-efficacy and goal effects revisited. Journal of Applied Psychology, 88(1), 87-99. doi: 10.1037/0021-9010.88.1.87

Baron, R. M., \& Kenny, D. A. (1986). The moderator-mediator variable distinction in social psychological research: conceptual, strategic, and statistical considerations. Journal of Personality and Social Psychology, 51(6), 1173-1183.

Bitner, M. J., Booms, B. H., \& Mohr, L. A. (1994). Critical service encounters: the employee's viewpoint. Journal of Marketing, 58(4), 95-106. doi: 10.1007/s11628-015-0284-z

Cavazotte, F., Moreno, V., \& Bernardo, J. (2013). Transformational leaders and work performance: the mediating roles of identification and self-efficacy. Brazilian Administration Review, 10(4), 490512. Retrieved from http://www.scielo.br/pdf/bar/v10n4/07.pdf. doi: 10.1590/S180776922013000400007

Chakrabarty, S., Brown, G., \& Widing, R. E. (2013). Distinguishing between the roles of customeroriented selling and adaptive selling in managing dysfunctional conflict in buyer-seller relationships. Journal of Personal Selling and Sales Management, 33(3), 245-260. doi: 10.2753/PSS0885-3134330301

Chen, G., Casper, W. J., \& Cortina, J. M. (2001). The roles of self-efficacy and task complexity in the relationships among cognitive ability, conscientiousness, and work-related performance: a metaanalytic examination. Human Performance, 14(3), 209-230. doi: 10.1207/S15327043HUP1403_1

Clark, K. D., \& Maggitti, P. G. (2012). TMT potency and strategic decision - making in high technology firms. Journal of Management Studies, 49(7), 1168-1193. doi: 10.1111/j.14676486.2012.01060.x

Gil, F., Rico, R., Alcover, C. M., \& Barrasa, Á. (2005). Change-oriented leadership, satisfaction and performance in work groups: effects of team climate and group potency. Journal of Managerial Psychology, 20(3/4), 312-328. doi: 10.1108/02683940510589073

Gist, M. E., \& Mitchell, T. R. (1992). Self-efficacy: a theoretical analysis of its determinants and malleability. Academy of Management Review, 17(2), 183-211.

Griffin, B., \& Hesketh, B. (2003). Adaptable behaviours for successful work and career adjustment. Australian Journal of Psychology, 55(2), 65-73. doi: 10.1080/00049530412331312914

Griffin, B., \& Hesketh, B. (2005). Are conscientious workers adaptable? Australian Journal of Management, 30(2), 245-259. doi: 10.1177/031289620503000204

Gully, S. M., Incalcaterra, K. A., Joshi, A., \& Beauien, J. M. (2002). A meta-analysis of team-efficacy, potency, and performance: interdependence and level of analysis as moderators of observed relationships. Journal of Applied Psychology, 87(5), 819-832. doi: 10.1037/0021-9010.87.5.819 
Guzzo, R. A., Yost, P. R., Campbell, R. J., \& Shea, G. P. (1993). Potency in groups: articulating a construct. British Journal of Social Psychology, 32(1), 87-106. doi: 10.1111/j.20448309.1993.tb00987.x

Hartline, M. D., \& Ferrell, O. C. (1996). The management of customer-contact service employees: an empirical investigation. Journal of Marketing, 60(4), 52-70. doi: 10.2307/1251901

Hayes, A. F. (2013). Introduction to mediation, moderation, and conditional process analysis: a regression-based approach. New York, NY: Guilford Press.

Hughes, D. E., Le Bon, J., \& Rapp, A. (2013). Gaining and leveraging customer-based competitive intelligence: the pivotal role of social capital and salesperson adaptive selling skills. Journal of the Academy of Marketing Science, 41(1), 91-110. doi: 10.1007/s11747-012-0311-8

Jones, G. R. (1986). Socialization tactics, self-efficacy, and newcomers' adjustments to organizations. Academy of Management Journal, 29(2), 262-279. doi: 10.2307/256188

Jong, A. de, Ruyter, K. de, \& Lemmink, J. (2004). Antecedents and consequences of the service climate in boundary-spanning self-managing service teams. Journal of Marketing, 68(2), 18-35. doi: 10.1509/jmkg.68.2.18.27790

Jong, A. de, Ruyter, K. de, \& Wetzels, M. (2005). Antecedents and consequences of group potency: a study of self-managing service teams. Management Science, 51(11), 1610-1625. doi: $10.1287 /$ mnsc. 1050.0425

Jong, A. de, Ruyter, K. de, \& Wetzels, M. (2006). Linking employee confidence to performance: a study of self-managing service teams. Journal of the Academy of Marketing Science, 34(4), 576-587. doi: $10.1177 / 0092070306287126$

Jung, D. I., \& Sosik, J. J. (2003). Group potency and collective efficacy examining their predictive validity, level of analysis, and effects of performance feedback on future group performance. Group \& Organization Management, 28(3), 366-391. doi: 10.1177/1059601102250821

Katzenbach, J. R., \& Smith, D. K. (1993). The wisdom of teams: creating the high-performance organization. New York, NY: Mckinsey \& Company. Inc.

Lai, M. C., \& Chen, Y. C. (2012). Self-efficacy, effort, job performance, job satisfaction, and turnover intention: the effect of personal characteristics on organization performance. International Journal of Innovation, Management and Technology, 3(4), 387-391. doi: 10.7763/IJIMT.2012.V3.260

Lester, S. W., Meglino, B. M., \& Korsgaard, M. A. (2002). The antecedents and consequences of group potency: a longitudinal investigation of newly formed work groups. Academy of Management Journal, 45(2), 352-368. doi: 10.2307/3069351

Lindell, M. K., \& Brandt, C. J. (2000). Climate quality and climate consensus as mediators of the relationship between organizational antecedents and outcomes. Journal of Applied Psychology, 85(3), 331-348. doi: 10.1037//0021-9010.85.3.331

Lira, E. M., Ripoll, P. P., Peiró, J. M., \& Orengo, V. V. (2008). How do different types of intragroup conflict affect group potency in virtual compared with face-to-face teams? A longitudinal study. Behaviour \& Information Technology, 27(2), 107-114. doi: 10.1080/01449290600875151

Marks, M. A., Mathieu, J. E., \& Zaccaro, S. J. (2001). A temporally based framework and taxonomy of team processes. Academy of Management Review, 26(3), 356-376. doi: 10.5465/AMR.2001.4845785 
Menguc, B., Auh, S., \& Uslu, A. (2013). Customer knowledge creation capability and performance in sales teams. Journal of the Academy of Marketing Science, 41(1), 19-39. doi: 10.1007/s11747012-0303-8

Monteiro, R. B. (2014). Studies on the role of work teams in professional performance: an analysis of Brazilian academic production in management from 2009 to 2013. Revista Interdisciplinar de Marketing, $\quad 4(2), \quad 18-30 . \quad$ Retrieved from http://periodicos.uem.br/ojs/index.php/rimar/article/view/26204/14140

Predmore, C. E., \& Bonnice, J. G. (1994). Sales success as predicted by a process measure of adaptability. Journal of Personal Selling \& Sales Management, 14(4), 55-65. doi: $10.1080 / 08853134$

Pulakos, E. D., Arad, S., Donovan, M. A., \& Plamondon, K. E. (2000). Adaptability in the workplace: development of taxonomy of adaptive performance. Journal of Applied Psychology, 85(4), 612624. doi: 10.1037//0021-9010.85.4.612

Schneider, B., Salvaggio, A. N., \& Subirats, M. (2002). Climate strength: a new direction for climate research. Journal of Applied Psychology, 87(2), 220-229. doi: 10.1037//0021-9010.87.2.220

Shrout, P. E., \& Bolger, N. (2002). Mediation in experimental and nonexperimental studies: new procedures and recommendation. Psychological Methods, 1(4), 422-45. doi: 10.1037//1082989X.7.4.422

Sparrowe, R. T., Liden, R. C., Wayne, S. J., \& Kraimer, M. L. (2001). Social networks and the performance of individuals and groups. Academy of Management Journal, 44(2), 316-325. doi: $10.2307 / 3069458$

Spiro, R. L., \& Weitz, B. A. (1990). Adaptive selling: conceptualization, measurement, and nomological validity. Journal of Marketing Research, 27(1), 61-69. doi: 10.2307/3172551

Tucker, J. S., Pleban, R. J., \& Gunther, K. M. (2010). The mediating effects of adaptive skill on valuesperformance relationships. Human Performance, 23(1), 81-99. doi: $10.1080 / 08959280903400275$

Verbeke, W. J., Belschak, F. D., Bakker, A. B., \& Dietz, B. (2008). When intelligence is (dys) functional for achieving sales performance. Journal of Marketing, 72(4), 44-57. doi: 10.1509/jmkg.72.4.44

Verbeke, W., Dietz, B., \& Verwaal, E. (2011). Drivers of sales performance: a contemporary metaanalysis. Have salespeople become knowledge brokers? Journal of the Academy of Marketing Science, 39(3), 407-428. doi: 10.1007/s11747-010-0211-8

Verhoef, P. C., \& Leeflang, P. S. H. (2009). Understanding the marketing department's influence within the firm. Journal of Marketing, 63(2), 14-37. doi: 10.1509/jmkg.73.2.14

Wang, G., \& Netemyer, R. G. (2002). The effects of job autonomy, customer demandingness, and trait competitiveness on salesperson learning, self-efficacy, and performance. Journal of the Academy of Marketing Science, 30(3), 217-228. doi: 10.1177\%2F00920703023030

Weitz, B. A., Sujan, H., \& Sujan, M. (1986). Knowledge, motivation, and adaptive behavior: a framework for improving-selling effectiveness. Journal of Marketing, 50(4), 174-191. doi: $10.2307 / 1251294$

Wood, R., \& Bandura, A. (1989). Social cognitive theory of organizational management. Academy of management Review, 14(3), 361-384. doi: 10.5465/AMR.1989.4279067

Zhao, X., Lynch, J. G., \& Chen, Q. (2010). Reconsidering Baron and Kenny: myths and truths about mediation analysis. Journal of Consumer Research 37(2), 197-206. doi: 10.1086/651257 


\section{Authors' Profiles}

Rodrigo Bastos Monteiro

Av. Colombo, 5790, 86700-000, Maringá, PR, Brazil. E-mail address: rodrigo@educacaoeap.com

Valter Afonso Vieira

Av. Colombo, 5790, 86700-000, Maringá, PR, Brazil. E-mail address: valterafonsovieira@ gmail.com 


\section{ANNEX A}

\section{Questionnaire}

Scale items

Factor loadings

Self-efficacy: (1986). KMO $=0.752 . \mathrm{VE}=52 \% .{ }^{3} \alpha=0.76$. Bartlett test Sig. $=0.000$.

My job is well within the scope of my abilities.

I have all the technical knowledge I need to deal with my job

I do not anticipate any problems in adjusting to work in this organization.

0.64

I feel confident that my skills and abilities equal or exceed those of my future colleagues.

0.70

I feel I am overqualified for the job I will be doing.

I could have handled a more challenging job than the one I will be doing.

Excluded

Adaptability: Spiro and Weitz (1990). KMO $=0.849$. VE $=58 \% . \alpha=0.87$. Bartlett test Sig. $=0.000$.

I vary my communication style from situation to situation.

I can easily use a wide variety of selling approaches.

It is easy for me to modify my sales presentation if the situation calls for it.

I am very flexible in the selling approach I use.

I feel confident that I can effectively change my planned presentation when necessary.

Basically I use different approaches with most customers.

I like to experiment with different professional approaches.

Team Potency: Guzzo et al $.(1993) . \mathrm{KMO}=0.852 . \mathrm{VE}=67 \% . \alpha=0.874$. Bartlett test Sig. $=0.000$

My team expects to be known as one of the top performing.

My team can get a lot done when we work hard.

My team can solve any problem.

My team has confidence in its abilities to perform at high levels.

My team believes that no job is too tough.

Interpersonal Climate Quality: Ahearne et al. (2010). KMO $=0.617 . \mathrm{VE}=65 \% . \alpha=0.73$. Bartlett test Sig. $=0.000$.

Conflict management: establishing conditions to prevent, control, or guide team conflict before it occurs.

Motivating and confidence building: generating and preserving a sense of collective confidence and motivation.

Affect management: regulating members' work related emotions.

Performance: Verhoef and Leeflang (2009). KMO $=0.827 . \mathrm{VE}=77 \% . \alpha=0.889$. Bartlett test Sig. $=0.000$.

Normally I reach my goal.

I have good performance at work.

I reach my goals at work.

I have high performance.

0.90

Note. $\mathrm{KMO}=$ Kaiser Meyer Olkin; $\mathrm{VE}=$ extracted variance; sig $=$ significance; $\alpha=$ Cronbach's alpha 


\section{ANNEX B}

\section{Adjustment Indices}

The adjustment indices for model measurement were estimated for three distinct samples. First for the entire model (with team and individual-level data), second for the team model alone $(\mathrm{n}=101)$ and third for the salespeople alone $(\mathrm{n}=290)$. The results are respectively: Adjusted Goodness Fit Index (AGFI) $=0.75 ; 0.88 ; 0.86$, Goodness Fit Index $(\mathrm{GFI})=0.80 ; 0.94 ; 0,91 ;$ Comparative Fit Index $(\mathrm{CFI})=0.84$; 0.94; 0.93; The Chi Square by degree of freedom $(\chi 2 / \mathrm{df})=3.54 ; 4.24 ; 2.79$, and Root Mean Square Error of Approximation $($ RMSEA $)=0.09 ; 0.11 ; 0.07$. 